\title{
THE EFFECT OF AIR-DRYING OF SOIL SAMPLES UPON SOME PHYSICAL SOIL PROPERTIES ${ }^{1}$ )
}

\author{
J. VAN SCHUYLENBORGH
}

(Laboratory of Soil Science and Plant Nutrition, Faculty of Agricultural Science,

University of Indonesia, Bogor)

\section{SUMMARY}

Results obtained with tropical soils show that air-drying of samples gives an erroneous picture of some physical properties (mechanical composition and consistency values) of these soils. When the soils are not dried at the air before analysing they appear to be much heavier than analysed after the usual drying process. Likewise the consistency values are lowered appreciably and the plastic number (or plasticity index) changes from that of plastic clay soils to that of coarse sands (see table 3). The origin of these irreversible changes in the physical state of soils by air-drying are discussed. The author concludes that it is not allowed to dry samples of tropical soils before analysing.

\section{INTRODUCTION}

It is customary to dry soil samples at the air before analysing. This drying may lead to changes in the chemical state of the soil, as was emphasized in a recent paper (van Scruylenborgh, 1953). As a consequence, the process of air-drying leads to an erroneous picture of the chemical properties of the soil and this is one of the reasons why, in many cases, soil analysis fails to be a reliable basis for fertilizing advices.

In this paper it will be shown that also physical characteristics, such as the mechanical composition and the ATrerserg consistency values of special tropical soils are profoundly affected by the process of drying.

\section{MATERIAL AND MEthods}

Samples were taken from three profiles of mountain soils in West Java, Indonesia, in the neighbourhood of the village Leuwiliang. The profiles are lying at an altitude of $1000 \mathrm{~m}$ and are grown with evergreen mountain forest. The rainfall is excessive and amounts to $7 \mathrm{~m}$ a year. The mean annual temperature at this altitude is about $25^{\circ} \mathrm{C}$. The profiles are developed in andesitic tuff and are of the type of brown forest, possibly weakly podzolized, soils.

The following is a typical profile.

$A_{00}$ 0-1 cm. Forest litter.

$A_{0}$ 1-3 " Very loose, crumbly, fine mull. Org. matter content $48.8 \%$.

A 3-13." Dark reddish brown (Munsell 5 YR $-3 / 2$ ), very porous, nutty structure, rich in humus (35.0\%), with many roots.

13-41 " Brown-dark brown (MunselL $10 \mathrm{YR}-4 / 3$ ), fine crumbly, with many roots and rich in humus (20.3\%).

41-76 „ Deep strongly. brown (Munsfle 7.5 YR - 5/6), rather compact. Org. matter content $7.2 \%$. Practically no roots.

B 76-100 " Brown to dark brown (Munsell 7.5 YR - 4/4), loose, loamy; org. matter content $4.2 \%$.

C $>100 "$ Yellowish brown, very porous, strongly weathered tuff. Org. matter content $1.6 \%$.

The mineralogical composition of the fraction $>50 \mu$ of the various horizons of this profile is given in table 1.

1) Received for publication June 10, 1953. 
Table 1. Mineral counts of the fraction $>50 \mu$ of the typical profile of a mountain soil from West-Java.

\begin{tabular}{|c|c|c|c|c|c|c|c|c|c|c|c|}
\hline Horizon & & 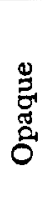 & 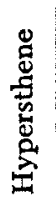 & 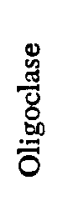 & 窎 & $\widehat{\widetilde{O}}$ & 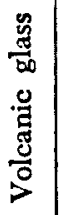 & 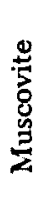 & $\frac{\stackrel{ \pm}{0}}{\frac{\stackrel{0}{0}}{0.0}}$ & 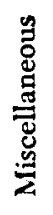 & Remarks \\
\hline $\begin{array}{lr}A_{0} & 1-3 \\
\text { A } & 3-13 \\
& 13-41 \\
& 41-76 \\
\text { B } & 76-100 \\
\text { C } & 100\end{array}$ & $\begin{array}{l}\text { cm } \\
" \\
" \\
"\end{array}$ & $\begin{array}{l}5 \\
5 \\
1 \\
6 \\
5 \\
2\end{array}$ & $\begin{array}{l}3 \\
5 \\
4 \\
4 \\
5 \\
7\end{array}$ & $\begin{array}{r}3 \\
6 \\
6 \\
3 \\
33 \\
31\end{array}$ & $\begin{array}{l}3 \\
4 \\
6 \\
6 \\
- \\
-\end{array}$ & $\begin{array}{r}31 \\
43 \\
12 \\
5 \\
- \\
-\end{array}$ & $\begin{array}{l}44 \\
27 \\
15 \\
14 \\
15 \\
24\end{array}$ & $\frac{2}{1}$ & $\begin{array}{l}- \\
\overline{-} \\
\overline{31} \\
15\end{array}$ & $\begin{array}{r}9 \\
9 \\
56 \\
60 \\
11 \\
21\end{array}$ & $\begin{array}{l}\text { 1) This silicic acid is } \\
\text { present as small tubes and } \\
\text { was deposited around root } \\
\text { hairs. X-ray analysis shows } \\
\text { it to be amorphous just as } \\
\text { the volcanic glass. }\end{array}$ \\
\hline
\end{tabular}

The profile description and the mineralogical analysis indicate the following characteristics. The organic matter content is very high and decreases gradually with the depth. There is an accumulation of $\mathrm{SiO}_{2}$ in the superficial soil layers and an accumulation of gibbsite in the B-horizon, which indicates a podzolizing process. It is, however, remarkable that there is no indication of an accumulation or translocation of iron (for a detailed mineralogical description, see: van RuMMELEN, 1953).

Samples from these profiles were taken and stored in paraffine paper bags, sealed as tight as possible and transported to the laboratory as soon as possible. After arriving the samples were divided into four portions. The first portion was kept moist; the second portion was oxidized with $\mathrm{I}_{2} \mathrm{O}_{2}$; the third portion was dried at the air and the fourth portion was dried at the air and oxidized with $\mathrm{H}_{2} \mathrm{O}_{2}$. Of all portions the mechanical composition was determined according to Morn (1910), with ammonia as peptizing agent.

To check the validity of this agent for the dispersion of tropical soils, the effect of several electrolytes was investigated by determining the fraction $<0.3 \mu$. Tre greater this fraction the better the peptization. The results are represented in table 2.

Table 2. The effect of electrolytes on dispersion, measured by the clay content (fraction $<0.3 \mu)$ of some Indonesian and Dutch soils.

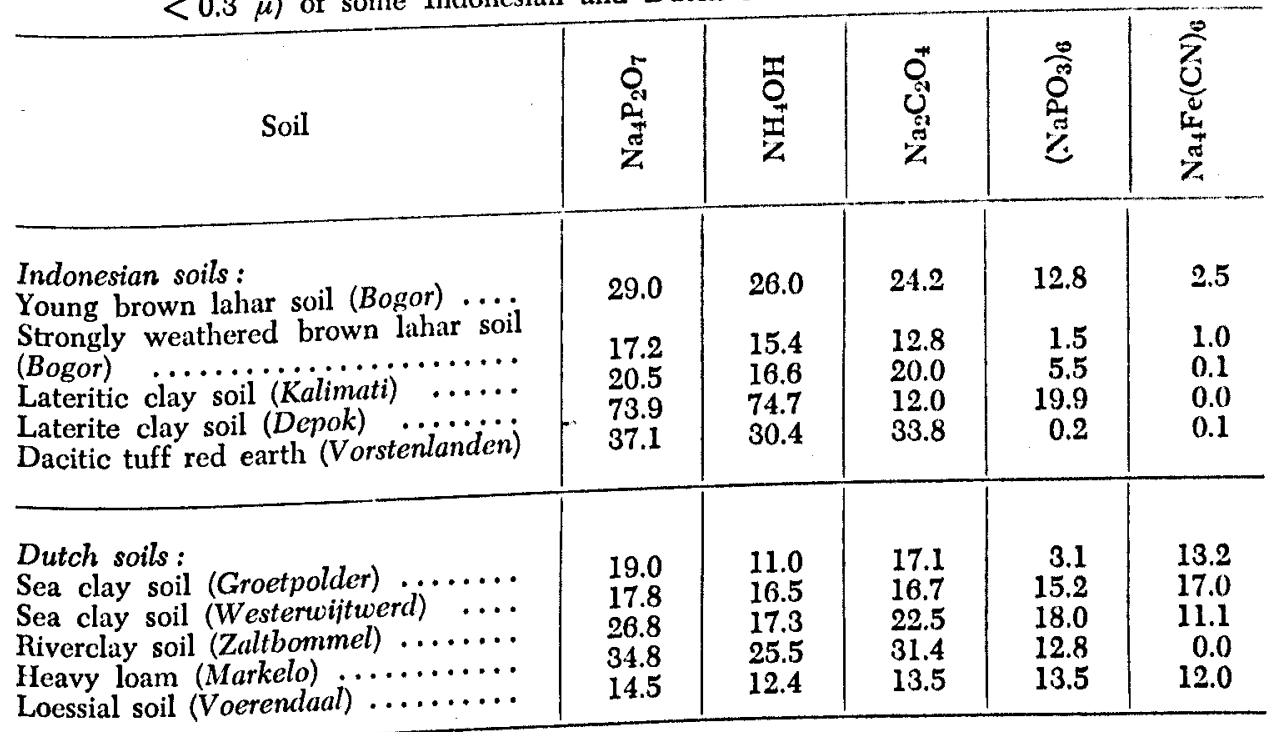


The table shows that sodium pyrophosphate is the best peptizing electrolyte both for tropical and for Dutch soils, followed by ammonia for Indonesian and by sodium oxalate for Dutch soils. It can be concluded that the use of ammonia for the dispersion of tropical soils is justified, because the values do not deviate much from the values obtained with sodium pyrophosphate.

The Atterberg consistency values of the moist and air-dried portions of the soil samples were determined according to MoHr (1915). The results, together with those of the mechanical analyses, are given in table 3.

\section{RESULts}

Generally spoken, the table shows that the effect of air-drying is that of changing a clay soil into a sand (compare the data for moist, oxidized and air-dried + oxidized). This is in accordance with the change in plastic number (from a plastic clay into a coarse sand, rich in organic matter) and the waterholding capacity.

The change in the mechanical composition is demonstrated especially in the clay fraction $(<2 \mu)$ and in the coarse fraction $(>50 \mu)$, the medium sized fractions being not altered very strongly, at least when comparing the results of the moist, oxidized and air-dried + oxidized portions. When the results of the moist and air-dried portions of the samples are compared, the process of airdrying can be detected in all fractions, the finer fractions (beyond $20 \mu$ ) being diminished and the coarser fractions being enlarged. Furthermore it appears that oxidation with $\mathrm{H}_{2} \mathrm{O}_{2}$ hardly changed the effect of air-drying: the fractions $<2 \mu$ and $>50 \mu$ of the air-dried and oxidized portions of the samples do not differ much from those of the air-dried portion, except in one case (II, 1-5 cm). This means, that the effect of air-drying is not an alteration of the organic matter but rather a change in the inorganic matter of the soil.

\section{Discussion}

The classification of soils is largely based on the mechanical composition of the soil and that of Indonesian soils also on the ATTERBERG consistency values. It is therefore necessary to have methods giving exact data of the true relationships in the soil. The results show, however, that air-drying of the soil before analysis gives a completely erroneous picture of both the mechanical composition and of the consistency values, at least for Indonesian mountain soils. It is probable that the physical properties of other soils also are affected by the process of air-drying.

It can be remarked $a$ priori that the effect of air-drying will depend upon three factors : 1 the climate; 2 the inorganic composition of the soil; 3 the organic matter of the soil.

The physical properties of soils in arid climates will not be affected strongly by air-drying, because they are completely dry already for long periods during the year. But in humid climates and especially under forest cover where the soils. It is probable that the physical properties of other soils are affected also effect of air-drying may be profound. This effect then is determined by the inorganic composition of the soil, when considering the results of the mechanical analyses, and by both the inorganic and organic composition, when considering the consistency values.

Puni and Keen (1925) already mentioned the fact that dehydration of the 
soil by drying, may result in a vigorous cementing action of the clay colloids on soil aggregates. The dispersion of such aggregates requires a rehydration of the clay particles and this rehydration may be very slow, especially when the clay content is large. This rehydration can then be accelerated by boiling and shaking.

In our case, however, the dehydration is, at least partly, irreversible. The clay fraction contains mainly amorphous substances as appeared from $\mathrm{X}$-ray analysis. The mineral counts, represented in table 1 , make it probable that these substances will very probably be gel-like silicic acid and volcanio glass. Silicic acid gels have the property of shrinking enormously on drying. During the drying process the gel structure alters appreciably with the result that, on rewetting, the original volume is not reached. Moreover, air has entered the gel structure and this air can hardly be removed on rewetting, so that the dispersion is incomplete (for details of the behaviour of silicic acid gels, see: van Bemmelen (1910) and Herarans (1949)). A second effect exerted by silicic acid gel in a dry state, is its vigorous cementation action; in this way other soil particles stick together to form larger aggregates. From these considerations it can be concluded that if soils such as those considered here, containing gellike silicic acids are dried at the air, the mechanical composition shifts to the coarse range (as shown in table 3), in the first place because of sticking action of silicic acid and secondly because of the impossibility to redisperse the silicic acid.

The above mentioned mechanism also explains why the consistency values have been lowered by drying the soil and why the plastic number changes from that of a plastic clay soil $(>15)$ to a coarse to medium sand $(<10)$.

The change in the consistency values may also be due to a change in the nature of the organic matter. There are several indications that sometimes organic matter cannot be wetted after drying, partly because of the absorption of air (Puchner, 1896 ; Enrenberg and Schultze, 1914 ; Tschapek, 1934 ; Lurkov, 1935 ; MEYERs, 1937), partly because of a polymerisation of organic molecules under the influence of Al-, Fe- or Si-compounds (Trulin, 1940; Hudig and ReDlich, 1940; Hudig and Siewertsz van Reesema, 1940), so that a hydrophobic humate is formed. Both phenomena prevent the water from penetrating into the pores of the aggregates and this leads to a lowering of the consistency values.

\section{Conclusion}

On the basis of the considerations, outlined above, it is advisable not to dry soil samples prior to analysing in the laboratory. The samples have to be analysed in a wet state and every measure must be taken to prevent drying out in the course of the analysis. This is difficult, especially for routine laboratories, but the changes caused by air-drying may be so profound that one has to accept these difficulties, especially for tropical soils, as the author believes to have shown.

\section{ACKNOWLEDGEMENT}

The author is indebted to Mr M. SoEpard, analytical chemist at the Institute of Soil Research, Bogor, Java, for his help in carrying out the physical analyses. 


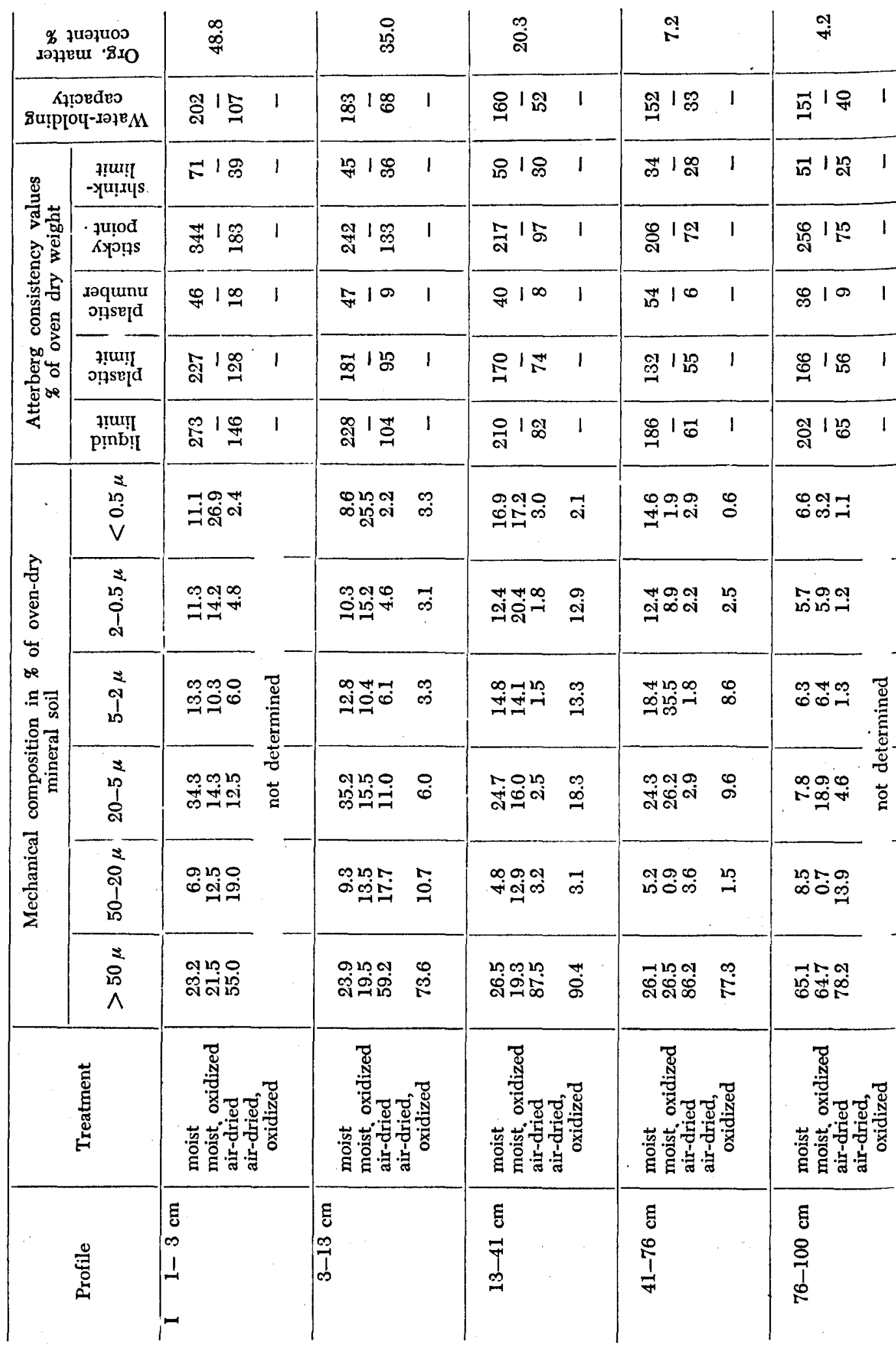




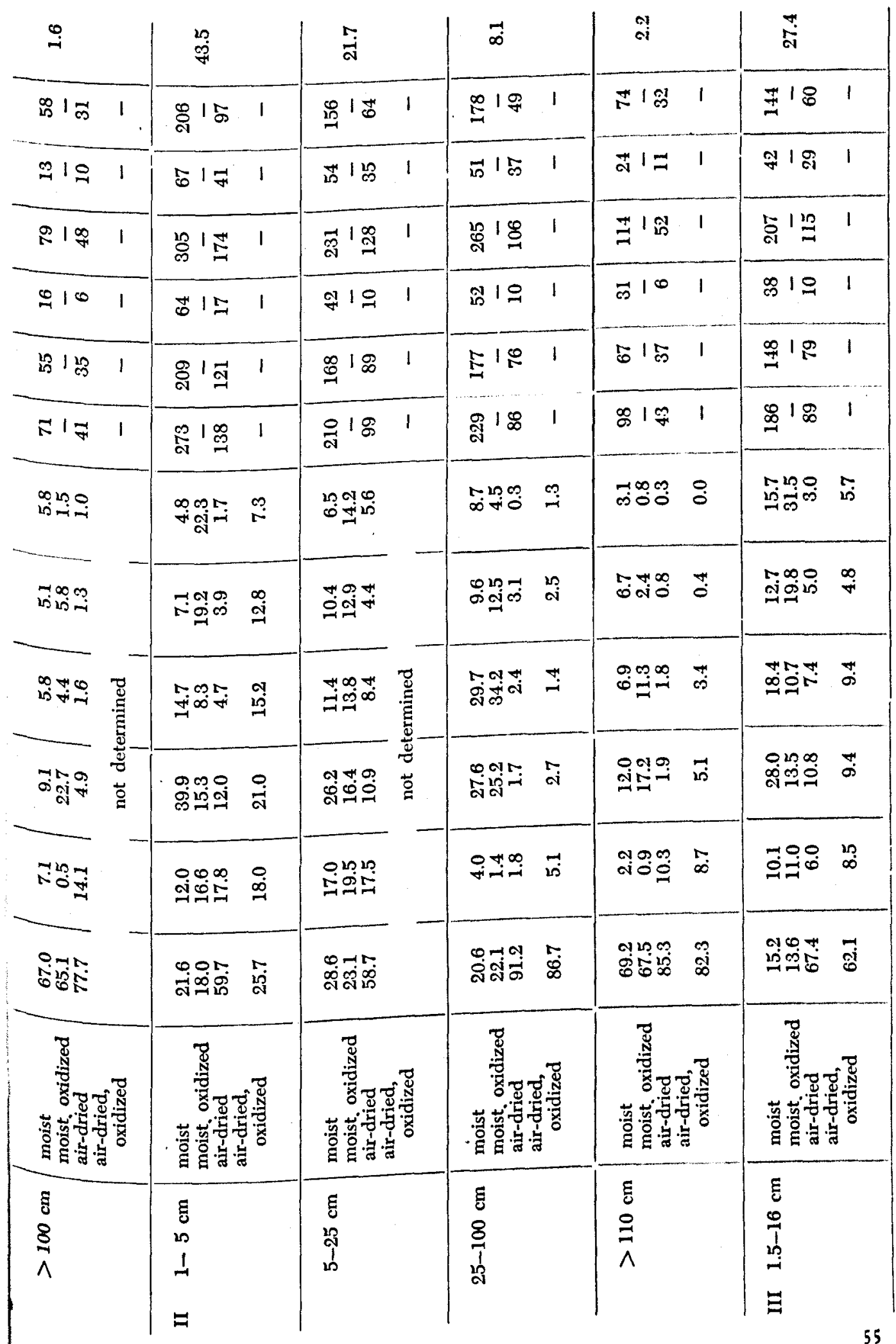




\begin{tabular}{|c|c|c|c|c|c|}
\hline \multirow{2}{*}{\multicolumn{2}{|c|}{ 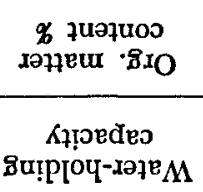 }} & \multicolumn{2}{|l|}{$\stackrel{\circ}{\mathscr{m}}$} & $\exists$ & i: \\
\hline & & $\exists 19$ & 1 & న 1001 & 81 ल 1 \\
\hline \multirow{5}{*}{ 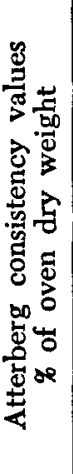 } & 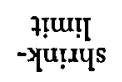 & เ 19 & 1 & สำ 1 & న్ల । న । \\
\hline & $\begin{array}{l}\text { zụ̣od } \\
\text { Kyp!̣s }\end{array}$ & $\infty 18$ & 1 & $\underset{\rightarrow}{m} 1 \mathfrak{N} \cdot 1$ & $\stackrel{\infty}{=} \mid \underset{1}{*} 1$ \\
\hline & $\begin{array}{l}\text { raquinu } \\
\text { ọ̣se [d }\end{array}$ & S & 1 & ส્ง |r 1 & $\stackrel{\sim}{\circ} 1 \infty \quad 1$ \\
\hline & 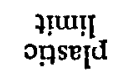 & 의 & 1 & $\stackrel{20}{\infty} \underset{\forall}{\infty} \quad 1$ & $\mathbb{N} \mid \stackrel{\infty}{\mathbb{N}}$ । \\
\hline & $\begin{array}{l}\text { q!uu!t } \\
\text { p!̣b!̣! }\end{array}$ & $\underset{\exists}{\stackrel{g}{\exists}} 10$ & 1 & 동 1 1 1 & $\infty 1001$ \\
\hline \multirow{6}{*}{ 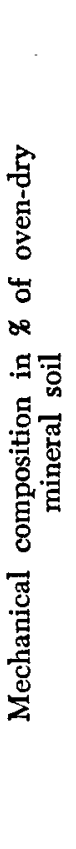 } & $\begin{array}{l}5 \\
109 \\
0 \\
V\end{array}$ & 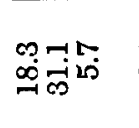 & $\stackrel{\circ}{\infty}$ & 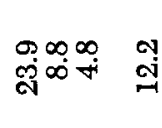 & 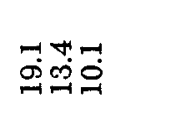 \\
\hline & $\begin{array}{c}3 \\
2 \\
0 \\
0 \\
0 \\
0 \\
1\end{array}$ & & $\ddot{0}$ & 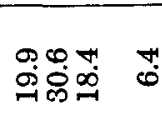 & ஸั \\
\hline & $\begin{array}{c}3 \\
0 \\
1 \\
0\end{array}$ & 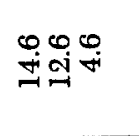 & $\infty$ & 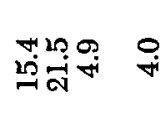 & 엄유 \\
\hline & $\begin{array}{c}2 \\
10 \\
1 \\
0\end{array}$ & 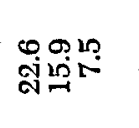 & के & 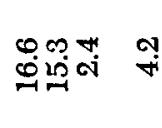 & $\begin{array}{ll}2000 \\
\operatorname{mog} \\
\operatorname{mog}\end{array}$ \\
\hline & 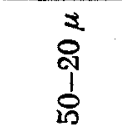 & 苛華華 & in & 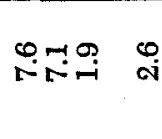 & 부유 \\
\hline & $\begin{array}{l}3 \\
1 \\
10 \\
1\end{array}$ & 웅무뭄 & $\ddot{\mathscr{C}}$ & 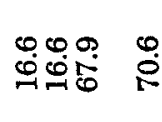 & 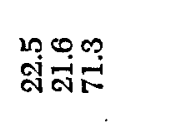 \\
\hline \multicolumn{2}{|r|}{ 苞 } & \multicolumn{2}{|c|}{ 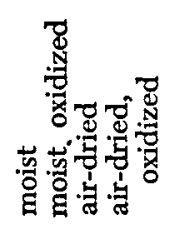 } & 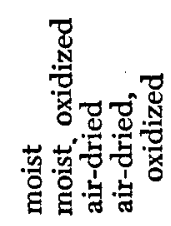 & 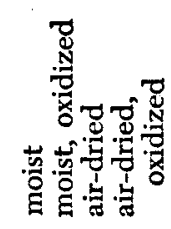 \\
\hline \multicolumn{2}{|r|}{ 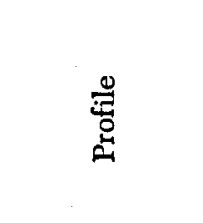 } & \multicolumn{2}{|l|}{$\begin{array}{l}\text { : } \\
0 \\
0 \\
0 \\
0\end{array}$} & $\begin{array}{l}E \\
0 \\
0 \\
1 \\
0\end{array}$ & $\begin{array}{l}\text { E } \\
\varnothing \\
\infty \\
\wedge\end{array}$ \\
\hline
\end{tabular}




\section{LITERATURE}

Bemmelen, J. M. van: Die Absorption. Dresden, 1910, 196-285.

Hermans, P. H. : in Kruyt's Colloid Chemistry II (1949). XII. Gels (529-536).

Ehrenberg, P. and K. Schultze : Kolloid-Z. 15 (1914) 183.

Hudig, J. and G. C. Redlich : Tijdschr. Nederl. Heidemij. 25 (1940) 382.

- - and N. H. Siewentsz van Reesema : Landbouwk. Tijdschr. 52 (1940) 529.

Luikov, A. V.: Ind. Eng. Chem. 27 (1935) 529.

Moнr, E. C. J. : Teysmania 7 (1910) 459.

- - : Meded. Lab. v. Agrogeol. en Grondonderz. No. 1 (1915).

Meyers, H. E. : Soil Sci. 44 (1937) 331.

Puchner, H. : Forsch. a. d. Geb. d. Agrikulturphysik 19 (1896).

Puri, A. N. and B. A. Keen : J. Agr. Sci. 15 (1925) 147.

Rummelen, F. F. F. E. vaN : in preparation.

SchuYlenBorgh, J. yan : De Bergcultures 22 (1953) 43.

Tschapex, M. W.: Kolloid-Z. 66 (1934) 91.

Tyulin, A. Тн. : Bodenk. u. Pfl.ern. 21/22 (1940) 544. 